\title{
A randomised control study of partial liquid ventilation after airway lavage with exogenous surfactant in a meconium aspiration syndrome animal model
}

\author{
Tomohiko Nakamura, Shigeyuki Matsuzawa, Masatoshi Sugiura, Masanori Tamura
}

\begin{abstract}
Aims-To test the hypothesis that lavage with exogenous surfactant before partial liquid ventilation in meconium aspiration syndrome (MAS) would improve debris removal, and therefore the effectiveness of partial liquid ventilation.

Methods-12 newborn piglets were randomised into 4 groups, partial liquid ventilation or gas ventilation, with and without surfactant lavage. Physiological and blood gas data were compared between groups by analysis of variance.

Results-Arterial oxygen pressure $\left(\mathrm{PaO}_{2}\right)$ was improved in the group treated with surfactant lavage when compared with the group not receiving surfactant. $\mathrm{PaO}_{2}$ in the group receiving surfactant lavage followed by partial liquid ventilation was further improved when compared with the group treated with surfactant lavage followed by gas ventilation and the group receiving partial liquid ventilation alone. Conclusion-The effectiveness of partial liquid ventilation in MAS might be enhanced by pretreatment with exogenous surfactant bronchial lavage.

(Arch Dis Child Fetal Neonatal Ed 2000;82:F160-F162)
\end{abstract}

Keywords: meconium aspiration syndrome; partial liquid ventilation; exogenous surfactant

Meconium aspiration syndrome (MAS) is a common cause of lung disease in neonates. Despite recent advances in neonatal respiratory care, infants with MAS continue to be candidates for extracorporeal membrane oxygenation, inhaled nitric oxide, and high mortality. ${ }^{12}$ The pathophysiology of MAS typically includes local obstruction of the airway by meconium debris with associated impairment of gas diffusion, patchy atelectasis, pulmonary vascular hypertension, and chemical pneumonitis. This pathophysiology can be explained, in part, by the mechanical obstruction of gas exchange by meconium, as well as meconium induced inhibition of surfactant activity. ${ }^{34}$ Liquid associated ventilation is a potential new treatment for MAS. ${ }^{5-7}$ The feasibility of using a perfluorochemical (PFC) as pulmonary lavage in total liquid ventilation has been demonstrated. ${ }^{56}$ Foust et al studied lung histology in an animal model of MAS and found that total liquid ventilation treated lungs were unobstructed, whereas those treated with partial liquid ventilation showed non- homogeneous aeration of alveoli and partial atelectasis. ${ }^{7}$ We hypothesised that lavage with exogenous surfactant before partial liquid ventilation would improve debris removal, and therefore the effectiveness of this treatment. To determine the effectiveness of exogenous surfactant and partial liquid ventilation in MAS, we performed partial liquid ventilation with and without previous exogenous surfactant treatment in a piglet model of acute MAS injury.

\section{Materials and methods}

Our study protocol was approved by the institutional animal care and use committee of the Nagano Children's Hospital in Nagano. Sixteen newborn piglets (1-3 days old; 0.9$1.5 \mathrm{~kg}$ ) were anaesthetised with intramuscularly administered ketamine $(10 \mathrm{mg} / \mathrm{kg} / \mathrm{dose})$ and atropine $(0.1 \mathrm{mg} / \mathrm{kg} / \mathrm{dose})$, and intubated with a 3.0 gauge endotracheal tube (Mallinkrodt Inc, St Louis, Missouri, USA). The animals were placed in the supine position. A right internal carotid artery line was placed for continuous blood pressure monitoring (Polygraph System; Nihon Koden, Tokyo, Japan). Anaesthesia was provided by ketamine $(5 \mathrm{mg} /$ $\mathrm{kg}$ /hour) and paralysis was maintained with pancronium bromide $(0.1 \mathrm{mg} / \mathrm{kg} /$ hour $)$. Ventilation was performed using a time cycle pressure limited ventilator (Hachidori 3; Senko Ika, Tokyo, Japan). All animals were maintained on $1.0 \mathrm{FIO}_{2}$ (fraction of inspired oxygen was 1.0) at a ventilator rate of 30 beats/minute with inspiratory pressure of $20 \mathrm{~cm} \mathrm{H}_{2} \mathrm{O}$, positive end expiratory pressure of $5 \mathrm{~cm} \mathrm{H}_{2} \mathrm{O}$, and inspiratory time of 1.0 second throughout the study. Oxygen saturation was continuously monitored by means of pulse oxymetry (N3000; Nellcor Inc, Hayward, California, USA), and arterial blood gases (ABL 505; Radiometer, Copenhagen, Denmark) were analysed intermittently. After baseline blood gas measurements, animals were given $5 \mathrm{ml} / \mathrm{kg}$ of $20 \%$ human meconium slurry via an endotracheal tube. The goal was to reduce the arterial oxygen pressure $\left(\mathrm{PaO}_{2}\right)$ to below $8 \mathrm{kPa}$. Repeat doses of meconium were administered as necessary to achieve a $\mathrm{PaO}_{2}$ value lower than $8 \mathrm{kPa}$ at 15 minutes after meconium instillation. The mean total amount of $20 \%$ human meconium slurry was $6.5 \mathrm{ml}$; there was no significant difference between groups. Animals were mechanically ventilated for one hour after meconium instillation to produce the lung injury model. This lung model has been used 
previously and is considered a reliable model of MAS. ${ }^{57}$ After one hour, four piglets, in which the $\mathrm{PaO}_{2}$ was over $13.3 \mathrm{kPa}$ or the arterial carbon dioxide pressure $\left(\mathrm{PaCO}_{2}\right)$ was over $12 \mathrm{kPa}$, were excluded from the study because they did not comply with the MAS model, and the remaining 12 piglets were randomised into two groups as surfactant lavage group or suction group.

The surfactant lavage group $(n=6)$ received four aliquots of $12 \mathrm{mg} / \mathrm{kg}$ of exogenous surfactant (surfactant-TA; Tokyo Tanabe, Tokyo, Japan) diluted in $2.5 \mathrm{ml}$ normal saline instilled into four different positions to promote distribution. Gentle manual ventilation was performed after each instillation, followed by repeated bronchial suctioning by means of a 6.5 gauge French suction catheter.

The suction group $(n=6)$ received tracheal suctioning with a 6.5 gauge French suction catheter until the suctioned fluid was clear.

Thirty minutes after bronchial lavage with exogenous surfactant or suction, blood gas sampling was performed, and then the animals were randomised to four groups as follows.

Group 1 (surfactant + partial liquid ventilation; $\mathrm{n}=3$ ). Preoxygenated PFC (Fluorinart 84; $3 \mathrm{M}$ Group, Osaka, Japan) was administered via the pressure monitoring port of the endotracheal tube over one to two minutes in an amount that approximated the animal's functional residual capacity, which was estimated by the visible meniscus of PFC in the endotracheal tube. The meniscus should be checked with no positive end expiratory pressure. Fluorinart is a PFC with a specific gravity of $1.73 \mathrm{~g} / \mathrm{cm}^{3}$ at $25^{\circ} \mathrm{C}$, surface tension of 13.0 dyne $/ \mathrm{cm}$, vapour pressure of $10.5 \mathrm{kPa}$ at $37^{\circ} \mathrm{C}$, and an $\mathrm{O}_{2}$ solubility of $59 \mathrm{ml} / 100 \mathrm{ml}$ and $\mathrm{CO}_{2}$ solubility of $224 \mathrm{ml} / 100 \mathrm{ml}$ at $37^{\circ} \mathrm{C}$ at one atmosphere of pressure.

Group 2 (surfactant + gas ventilation; $\mathrm{n}=3$ ). Animals were maintained after surfactant lavage at the same ventilator setting throughout the study.

Group 3 (suction + partial liquid ventilation; $\mathrm{n}=3$ ) received PFC as group 1 after bronchial suction.

Group 4 (suction + gas ventilation; $\mathrm{n}=3$ ) received no PFC and bronchial suction.

STATISTICAL ANALYSIS

Physiological parameters were expressed as mean (SEM) and were compared using analysis of variance (ANOVA) for repeated measures with Fisher's tests. A significant difference was set at $\mathrm{p}<0.05$.

\section{Results}

Figure 1 shows changes in $\mathrm{PaO}_{2}$ over time. After bronchial lavage with surfactant, $\mathrm{PaO}_{2}$ was significantly greater than in those animals that had not been treated with surfactant. In addition, $\mathrm{PaO}_{2}$ in group 1 (surfactant + partial liquid ventilation) remained significantly higher than the other groups at 30 minutes after the initiation of partial liquid ventilation. Figure 2 shows the $\mathrm{PaCO}_{2}$ values. After bronchial lavage with surfactant, $\mathrm{PaCO}_{2}$

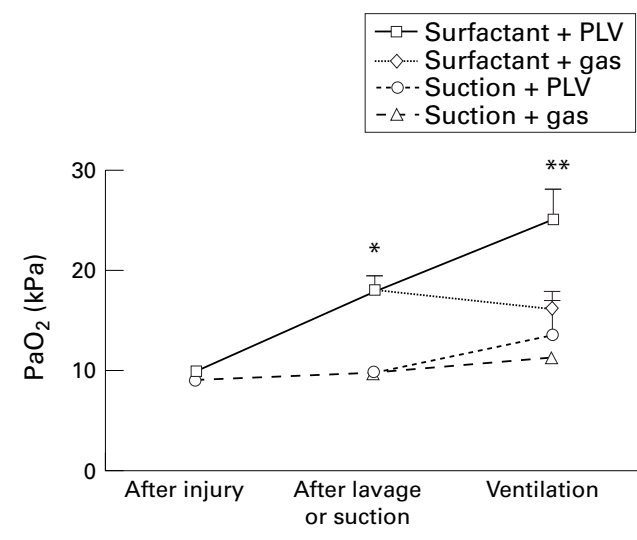

Figure $1 \quad \mathrm{PaO}_{2}$ data are illustrated. After the bronchial lavage with exogenous surfactant, $\mathrm{PaO}$ values were significantly greater than in the no surfactant lavage groups $\left({ }^{*} p<0.05\right.$ surfactant lavage group versus no surfactant lavage group). In addition, $\mathrm{PaO}_{2}$ values in the "surfactant $+P L V$ " group remained significantly higher than the other groups after the initiation of PLV (** $p<0.05$ for the "surfactant + PLV" group versus the "surfactant + gas" and "suction + PLV" groups; $p<0.01$ for the "surfactant + PLV" versus "suction + gas" group). $\mathrm{PaO}_{2}$, arterial oxygen pressure; PLV, partial liquid ventilation.



Figure 2 The $\mathrm{PaCO}_{2}$ data are illustrated. The surfactant lavage groups tended to have lower $\mathrm{PaCO}_{2}$ values than the no surfactant lavage groups, but the difference was not significant. The "surfactant + PLV" group had significantly lower $\mathrm{PaCO}_{2}$ values than the "suction + gas" group after the initiation of $P L V\left({ }^{*} p<0.05\right.$ for the "surfactant + PLV" group versus "suction + gas group"). $\mathrm{PaCO}_{2}$, arterial carbon dioxide pressure; PLV, partial liquid ventilation.

tended to decrease compared with the group that did not receive surfactant, although the difference was not significant. After the initiation of partial liquid ventilation, group 1 (surfactant + partial liquid ventilation) had significantly lower $\mathrm{PaCO}_{2}$ values than group 4 (suction + gas ventilation).

\section{Discussion}

The lung pathophysiology associated with MAS in the newborn infant includes airway obstruction, impaired gas diffusion, pulmonary vascular hypertension, and pulmonary inflammation. To achieve effective meconium debris removal without inactivating or washing out surfactant, a bronchial lavage with exogenous surfactant has been proposed. ${ }^{89}$ In addition, total liquid ventilation with PFC might also remove meconium debris, without removing surfactant. ${ }^{56}$ In a meconium strained lamb model, Foust and others reported that total 
liquid ventilation with PFC improved alveolar recruitment and improved compliance when compared with control gas ventilated animals. ${ }^{7}$ In addition, the lung histology of the total liquid ventilation group demonstrated clear, intact alveolar epithelium and homogeneously expanded alveoli, whereas non-homogeneous aeration of alveoli and partial atelectasis was seen in the partial liquid ventilation group. We speculated that PFC in partial liquid ventilation would not be as effective as saline or surfactant at debris removal and partial liquid ventilation after surfactant lavage would optimise the effectiveness of partial liquid ventilation in the MAS model.

In our study, we evaluated the effectiveness of a combined surfactant lavage with partial liquid ventilation in a piglet model of MAS. When the animals were treated with exogenous surfactant lavage after injury but preceding partial liquid ventilation, improvement in gas exchange was observed. In contrast, without previous surfactant lavage, these improvements were not seen after partial liquid ventilation. These results suggest that pretreatment of infants with MAS with a surfactant lavage might improve the efficacy of partial liquid ventilation by optimising debris removal and improving the distribution of ventilation during partial liquid ventilation. The use of a combined exogenous surfactant and partial liquid ventilation has also been shown to be effective in a surfactant deficient animal model. ${ }^{10}{ }^{11}$ In this model, exogenous surfactant might improve spreading and uniform distribution of the PFC by reducing surface tension at the alveolar surface before the initiation of partial liquid ventilation. This mechanism might, in fact, also be present in the MAS model used in our study.

Therefore, our results suggest that improvement in lung function with partial liquid ventilation in MAS might be enhanced by pretreatment with exogenous surfactant bronchial lavage.

We gratefully acknowledge Mr M Taniguti (Nihon Koden Co, Matsumoto, Japan) for his technical support. This work was funded by a grant from the Japanese Health Ministry.

1 The Neonatal Inhaled Nitric Oxide Study Group. Inhaled nitric oxide in full-term and nearly full-term infants with hypoxic respiratory failure. $N$ Engl f Med 1997;336:597604 .

2 Roberts JD, Fineman JR, Morin FC, et al. Inhaled nitric oxide and persistent pulmonary hypertension of the newborn. N Engl f Med 1997;336:605-10.

3 Bae CW, Takahashi A, Chida S, Sasaki M. Morphology and function of pulmonary surfactant inhibited by meconium. Pediatr Res 1998;44:187-91.

4 Cleary GM, Antunes MJ, Ciesielka DA, Higgins ST, Spitzer AR, Chander A. Exudative lung injury is associated with decreased levels of surfactant proteins in a rat model of decreased levels of surfactant proteins in a rat mod
meconium aspiration. Pediatrics 1997;100:998-1003.

5 Marraro G, Bonati M, Ferrari A, et al. Perfluorocarbon Marraro $G$, Bonati $M$, Ferrari A, et al. Perfluorocarbon
broncho-alveolar lavage and liquid ventilation versus saline broncho-alveolar lavage in adult guinea pig experimental model of meconium inhalation. Intensive Care Med 1998;24:501-8

6 Shaffer TH, Lowe CA, Bhutani VK, Douglas PR. Liquid ventilation: effects on pulmonary function in distressed meconium strained lambs. Pediatr Res 1984;18:47-52.

7 Foust R, Tran NN, Cox C, et al. Liquid assisted ventilation: an alternative ventilatory strategy for acute meconium aspiration injury. Pediatr Pulmonol 1996;21:316-22.

8 Cochrane CG, Revak SD, Merritt TA, et al. Bronchoalveolar lavage with KL4-surfactant in models of meconium lavage with KL4-surfactant in models of mecor

9 Paranka MS, Walsh WF, Stancombe BB. Surfactant lavage in a piglet model of meconium aspiration syndrome. Pediin a piglet model of mecon

10 Mrozek JD, Smith KM, Bing DR, et al. Exogenous surfactant and partial liquid ventilation: physiologic and pathologic effects. Am $f$ Respir Crit Care Med 1997; 156:1058-65.

11 Tarczy-Hornoch P, Hildebrandt J, Standaert TA, Jackson JC. Surfactant replacement increases compliance in premature lamb lungs during partial liquid ventilation in situ. F Appl Physiol 1998;84:1316-22. 